\title{
Shrinkage and restrained shrinkage cracking of self-compacting concrete compared to conventionally vibrated concrete
}

\author{
R. Loser - A. Leemann
}

Received: 7 June 2007 / Accepted: 25 February 2008/Published online: 4 March 2008

(C) RILEM 2008

\begin{abstract}
Self-compacting concrete (SCC) used in Switzerland contains about $80 \mathrm{l} / \mathrm{m}^{3}$ more volume of paste than conventionally vibrated concrete (CVC). Consequently, there are some systematic differences in the properties of the hardened concrete. Normally, shrinkage of SCC is higher than shrinkage of CVC. Therefore, risk of cracking in case of restrained deformations can be increased for SCC. In this study shrinkage of thirteen different SCC mixtures using volume of paste, water content, type of binder, grain size distribution or content of shrinkage reducing admixture (SRA) as variables was compared with shrinkage of three different CVC mixtures with constant volume of paste but variable w/b. Furthermore, the risk of cracking of the different SCC- and CVC-mixtures in restrained conditions was studied under constant and varying curing conditions. The results show that shrinkage is mainly depending on volume of paste. Due to the higher volume of paste, SCC displayed higher shrinkage than CVC. Adding an SRA was the only measure to reduce shrinkage of SCC to values of CVC. Restrained shrinkage cracking is depending on shrinkage rate, mechanical properties and drying velocity. For slow shrinkage stress
\end{abstract}

R. Loser $(\bowtie) \cdot$ A. Leemann

Laboratory for Concrete/Construction Chemistry, Empa (Swiss Federal Laboratories for Materials Testing and Research), Überlandstr. 129, 8600 Dubendorf,

Switzerland

e-mail: roman.loser@empa.ch development, cracking risk of SCC can be lower compared to CVC despite the higher shrinkage rate.

Keywords Shrinkage - Shrinkage cracking ·

Relaxation - Self-compacting concrete ·

Mix design

\section{Introduction}

The development of self-compacting concrete (SCC) has opened new possibilities in the building industry due to its unique flow behaviour [1]. A wide variety of mix designs are used to produce SCC depending on the methodical approach and the raw materials available. SCC used in Switzerland has a relatively low binder content and its rheological properties are characterised by a low viscosity and a high yield stress in comparison with SCC made in Sweden or Japan, for example [2, 3]. In contrary to other countries where there is no substantial difference between the volume of paste of SCC and conventionally vibrated concrete (CVC) [4-6], SCC in Switzerland contains about $80 \mathrm{l} / \mathrm{m}^{3}$ more volume of paste than CVC. Consequently, there are some systematic differences in the properties of the hardened concrete [7]. One of the most important properties regarding the design and the durability of structures is shrinkage which seems to be increased for SCC [8]. Shrinkage of concrete in its hardened 
state can be divided in two different processes [9]. The first and main process is drying shrinkage caused by water loss of concrete exposed to unsaturated air. The second process is autogenous shrinkage that mainly has an effect on concrete with low water-tobinder ratio (w/b). Shrinkage can have implications on the risk of cracking. If deformations caused by shrinkage are restrained, tensile stresses are developing in concrete. Cracks occur as soon as tensile stress exceeds tensile strength. Cracks have a considerable influence on durability of concrete structures because ingress of chlorides and carbonation are accelerated and should therefore be prevented. Measures to reduce risk of cracking either have to be based on an adaptation of material properties or a control of the relation between stress development and relaxation.

In this study the influence of mix design on shrinkage of SCC in the hardened state is investigated. Furthermore, the risk of cracking of the different mixtures in restrained conditions is studied and compared to the one of CVC. For two selected mixtures the behaviour in case of restrained shrinkage deformations is assessed for different curing times and drying velocities. In order to improve the evaluation of the results, E-modulus, flexural strength and creep are measured at different ages.

\section{Experimental program}

As aggregate natural sand and gravel with a high percentage of well-rounded particles was used (maximum grain size: $16 \mathrm{~mm}$ for SCC and $32 \mathrm{~mm}$ for CVC). The different types of cements and mineral admixtures used were ordinary Portland cement CEM I $42.5 \mathrm{~N}$ (OPC), CEM II/A - LL $42.5 \mathrm{~N}$ (CEM II), low $\mathrm{CaO}$ fly ash (FA) and limestone powder (LP, Table 1).
Whenever fly ash was used, it replaced cement by $23 \%$ by weight ( $30 \%$ by volume), while limestone powder replaced cement by $27 \%$ by weight ( $30 \%$ by volume, Table 2). A polycarboxylate type superplasticizer (SP) and a shrinkage reducing admixture (SRA) based on hydroxyl compounds were used. The volume of paste as specified in Table 2 includes cement, fly ash, limestone powder, water, superplasticizer and SRA. Five different SCC mixtures (SCC 1/5) using the volume of paste and the water content as variables and three different mixtures of CVC with constant volume of paste but variable w/b were produced. Furthermore, eight SCC mixtures $(\mathrm{SCC} \mathrm{A} / \mathrm{H})$ with changes in type of binder, grain size distribution of the aggregates or the addition of SRA were produced in order to study their influence on shrinkage (Table 2). These eight mixtures have the identical volume of paste as SCC 1 which is used as a reference. The mix design applied is based on the volume of voids present between aggregate particles and a certain amount of surplus paste [10]. The workability of SCC was determined by measuring flow (without knocking) and flow time in the L-box [1]. For CVC the flow was measured according to [11].

Compressive strength, flexural strength and E-modulus were measured on prisms $120 \mathrm{~mm} \times 120$ $\mathrm{mm} \times 360 \mathrm{~mm}$ at the age of 28 days. For measuring E-modulus, the load was increased from 0.5 MPa to $1 / 3$ of compressive strength for three times. At the third loading the belonging difference in deformation was measured. Free shrinkage (called "shrinkage" in the following context) and creep were determined on prisms $120 \mathrm{~mm} \times 120 \mathrm{~mm} \times 360 \mathrm{~mm}$ up to the age of 91 days according to [12] under curing condition K0 (Table 3). Start of shrinkage measurements was at the age of $24 \mathrm{~h}$, while a constant load of $10 \mathrm{MPa}$ was applied to the samples for the creep measurements at the age of 28 days. Creep was then determined as the

Table 1 Characteristics of the different binders

\begin{tabular}{lccclllllll}
\hline Type & $\begin{array}{l}\mathrm{CaO} \\
(\%)\end{array}$ & $\begin{array}{l}\mathrm{SiO}_{2} \\
(\%)\end{array}$ & $\begin{array}{l}\mathrm{Al}_{2} \mathrm{O}_{3} \\
(\%)\end{array}$ & $\begin{array}{l}\mathrm{Fe}_{2} \mathrm{O}_{3} \\
(\%)\end{array}$ & $\begin{array}{l}\mathrm{MgO} \\
(\%)\end{array}$ & $\begin{array}{l}\mathrm{Na}_{2} \mathrm{O}_{\mathrm{eq}} \\
(\%)\end{array}$ & $\begin{array}{l}\mathrm{SO}_{3} \\
(\%)\end{array}$ & $\begin{array}{l}\text { Blaine } \\
\left(\mathrm{cm}^{2} / \mathrm{g}\right)\end{array}$ & $\begin{array}{l}\text { Loss of } \\
\text { ignition }(\%)\end{array}$ & $\begin{array}{l}\text { Density } \\
\left(\mathrm{kg} / \mathrm{m}^{3}\right)\end{array}$ \\
\hline OPC & 63.6 & 19.4 & 4.7 & 2.9 & 1.7 & 0.7 & 3.4 & 3,040 & 2.7 & 3,130 \\
CEM II & 60.9 & 17.0 & 4.0 & 2.4 & 1.5 & 0.6 & 3.0 & 3,710 & 7.2 & 3,070 \\
FA & 6.0 & 56.0 & 22.8 & 6.9 & 2.4 & 1.0 & 0.9 & 2,670 & 3.5 & 2,220 \\
LP & 53.8 & 0.6 & 0.2 & 0.1 & 1.5 & - & - & 4,480 & 43.8 & 2,765 \\
\hline
\end{tabular}


Table 2 Composition and workability of SCC and CVC mixtures

\begin{tabular}{|c|c|c|c|c|c|c|c|c|c|c|c|c|}
\hline \multirow[t]{2}{*}{ Mixture } & \multirow{2}{*}{$\begin{array}{l}\text { Aggregate } \\
\left(\mathrm{kg} / \mathrm{m}^{3}\right)\end{array}$} & \multirow[t]{2}{*}{$\mathrm{s} / \mathrm{g}$} & \multirow{2}{*}{$\begin{array}{l}\mathrm{OPC} \\
\left(\mathrm{kg} / \mathrm{m}^{3}\right)\end{array}$} & \multicolumn{2}{|c|}{ Cement/mineral admixture } & \multirow{2}{*}{$\begin{array}{l}\text { Water } \\
\left(\mathrm{kg} / \mathrm{m}^{3}\right)\end{array}$} & \multirow[t]{2}{*}{$\mathrm{w} / \mathrm{b}$} & \multirow{2}{*}{$\begin{array}{l}\text { SP } \\
\left(\mathrm{kg} / \mathrm{m}^{3}\right)\end{array}$} & \multirow{2}{*}{$\begin{array}{l}\text { SRA } \\
\left(\mathrm{kg} / \mathrm{m}^{3}\right)\end{array}$} & \multirow{2}{*}{$\begin{array}{l}\text { Vol. of } \\
\text { paste } \\
\left(1 / \mathrm{m}^{3}\right)\end{array}$} & \multirow{2}{*}{$\begin{array}{l}\text { Flow } \\
(\mathrm{cm})\end{array}$} & \multirow{2}{*}{$\begin{array}{l}\text { L-box } \\
\text { (s) }\end{array}$} \\
\hline & & & & Type & $\left(\mathrm{kg} / \mathrm{m}^{3}\right)$ & & & & & & & \\
\hline CVC 1 & 1,938 & 0.54 & 351 & - & - & 139 & 0.40 & 2.6 & - & 254 & 52 & - \\
\hline CVC 2 & 1,937 & 0.54 & 310 & - & - & 155 & 0.50 & - & - & 254 & 47 & - \\
\hline CVC 3 & 1,938 & 0.54 & 276 & - & - & 166 & 0.60 & - & - & 254 & 53 & - \\
\hline SCC 1 & 1,734 & 1.00 & 455 & - & - & 178 & 0.40 & 5.5 & - & 329 & 63 & 3.7 \\
\hline SCC 2 & 1,679 & 1.00 & 512 & - & - & 179 & 0.36 & 6.1 & - & 349 & 65 & 2.6 \\
\hline SCC 3 & 1,787 & 1.00 & 407 & - & - & 181 & 0.45 & 4.3 & - & 316 & 62 & 2.5 \\
\hline SCC 4 & 1,732 & 1.00 & 435 & - & - & 199 & 0.46 & 3.9 & - & 342 & 63 & 1.3 \\
\hline SCC 5 & 1,734 & 1.00 & 489 & - & - & 166 & 0.35 & 8.8 & - & 332 & 67 & 3.8 \\
\hline SCC A & 1,735 & 1.00 & - & CEM II & 452 & 178 & 0.40 & 5.0 & - & 330 & 60 & 1.8 \\
\hline SCC B & 1,738 & 1.00 & 322 & FA & 98 & 178 & 0.43 & 3.8 & - & 329 & 72 & 1.8 \\
\hline SCC C & 1,734 & 1.00 & 350 & FA & 106 & 166 & 0.37 & 4.6 & - & 331 & 69 & 3.0 \\
\hline SCC D & 1,733 & 1.00 & 327 & LP & 124 & 178 & 0.40 & 4.1 & - & 331 & 71 & 2.6 \\
\hline SCC E & 1,739 & 1.22 & 453 & - & - & 177 & 0.40 & 6.8 & - & 329 & 70 & 3.5 \\
\hline SCC F & 1,738 & 0.73 & 461 & - & - & 177 & 0.39 & 4.6 & - & 329 & 66 & 2.4 \\
\hline SCC G & 1,738 & 1.00 & 454 & - & - & 174 & 0.40 & 5.5 & 4.5 & 329 & 68 & 2.6 \\
\hline SCC H & 1,738 & 1.00 & 454 & - & - & 170 & 0.40 & 5.0 & 9.1 & 329 & 70 & 2.8 \\
\hline
\end{tabular}

s/g: Sand/gravel-ratio, OPC: Ordinary Portland cement (CEM I), CEM II: CEM II/A-LL 42.5 N, FA: Fly ash, LP: Limestone powder, SP: Superplasticizer, SRA: Shrinkage reducing admixture

Table 3 Definition of the different curing conditions used

\begin{tabular}{|c|c|c|c|c|c|}
\hline Condition & $\begin{array}{l}\text { Curing at } 20^{\circ} \mathrm{C} / 99 \% \\
\text { r.h. (days) }\end{array}$ & $\begin{array}{l}\text { Storage at } 20^{\circ} \mathrm{C} / 90 \% \\
\text { r.h. (days) }\end{array}$ & $\begin{array}{l}\text { Storage at } 20^{\circ} \mathrm{C} / 70 \% \\
\text { r.h. (days) }\end{array}$ & $\begin{array}{l}\text { Storage at } 20^{\circ} \mathrm{Cl} \\
35 \% \text { r.h. (days) }\end{array}$ & Comment \\
\hline K0 & 0 & 1 & 90 & - & $\begin{array}{l}\text { All mixtures, creep and } \\
\text { shrinkage }\end{array}$ \\
\hline K1 & 2 & 0 & 12 & Until cracking & $\begin{array}{l}\text { All mixtures, restrained } \\
\text { shrinkage }\end{array}$ \\
\hline $\mathrm{K} 2$ & 2 & 0 & Until cracking & - & CVC 2 and SCC 4 only \\
\hline K3 & 7 & 0 & Until cracking & - & CVC 2 and SCC 4 only \\
\hline K4 & 14 & 0 & Until cracking & - & CVC 2 and SCC 4 only \\
\hline K5 & 7 & 14 & Until cracking & - & CVC 2 and SCC 4 only \\
\hline
\end{tabular}

difference from total deformation minus elastic and shrinkage deformation. Creep values are referred to concrete age and were measured for selected mixtures only. After placement, all samples were stored at $20^{\circ} \mathrm{C}$ and $90 \%$ relative humidity (r.h.) for 1 day (samples for shrinkage and creep measurements) respectively for 2 days (samples for measuring compressive strength, flexural strength and E-modulus). Afterwards all samples were moved to a room with a temperature of $20^{\circ} \mathrm{C}$ and $70 \%$ r.h. In addition to creep measurements under constant load applied after 28 days, creep of CVC 2 and SCC 4 was measured on seperate prisms $120 \mathrm{~mm} \times 120 \mathrm{~mm} \times 360 \mathrm{~mm}$ under increasing load at $70 \%$ r.h. The loading started after 2 days of curing. The chosen load increase was derived from a typical shrinkage curve (Fig. 1) and should express realistic changing state of stress in case of restrained shrinkage and not only a material constant as derived from constant loading after 28 days. 


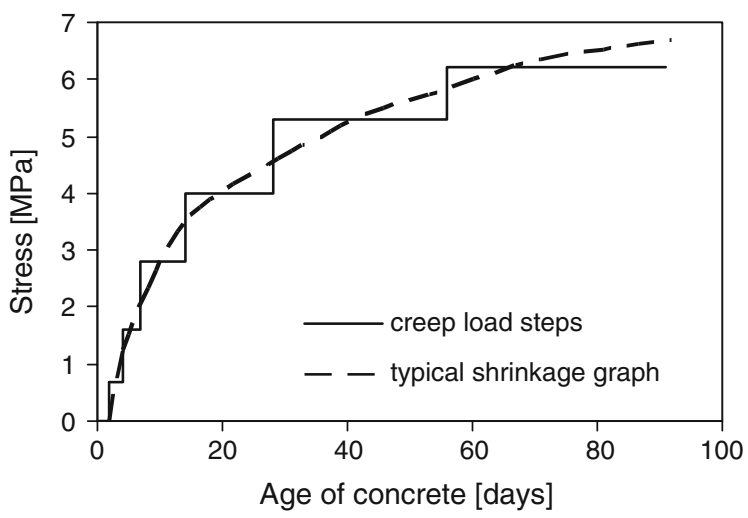

Fig. 1 Load steps for creep measurements under increasing load (CVC 2 and SCC 4)

Restrained shrinkage cracking (called "restrained shrinkage" in the following context) was investigated using concrete with predetermined breaking points cast around a steel square (Fig. 2). The normal cross-section of the concrete was $100 \mathrm{~mm} \times 100 \mathrm{~mm}$ which was reduced to $60 \mathrm{~mm} \times 100 \mathrm{~mm}$ in the area of the predetermined breaking points. The square steel profile responsible for the restraint (cross-section $16 \mathrm{~mm} \times 100 \mathrm{~mm}$ ) had rounded corners and was strengthened by two diagonally welded flat steels (cross-section $20 \mathrm{~mm} \times 100 \mathrm{~mm}$ ). As the concrete shrinks compressive stress is produced in the steel, which is balanced by a tensile stress in concrete. To avoid cracks in the corners of the concrete square, they were reinforced with rebars of $8 \mathrm{~mm}$ in diameter and $200 \mathrm{~mm}$ in length. Drying of the samples was possible from all the surfaces except the one covered by the square steel profile.

All samples (one square per mixture) were stored under identical conditions (K1) as follows: After production they were first cured at $20^{\circ} \mathrm{C}$ and $\sim 99 \%$ r.h. (wrapped in wet towels) for 2 days, afterwards they were moved to $20^{\circ} \mathrm{C}$ and $70 \%$ r.h. for 12 days and finally the specimens were stored at $20^{\circ} \mathrm{C}$ and $35 \%$ r.h. until the end of measurements to accelerate stress development (Table 3). The specimens were visually monitored on a daily basis to determine the time of crack appearance (age of cracking). At the beginning, it was the aim to produce more than one crack per specimen. Therefore, the square-set up was used instead of the well known ring test. However, the tensile stress in the square was reduced after the a

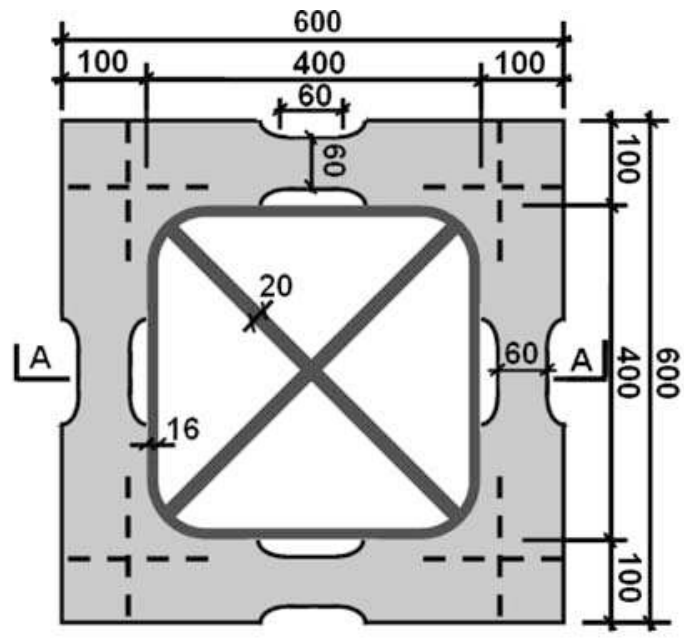

Section A-A:

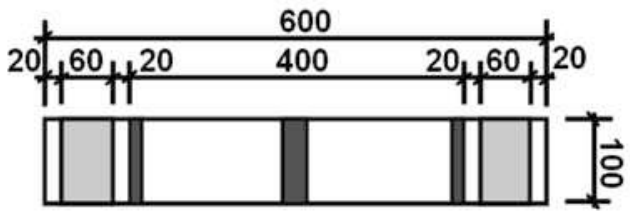

b

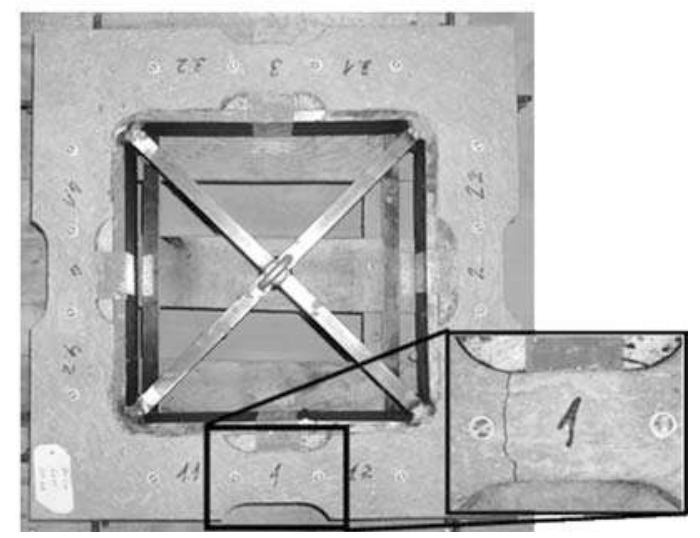

Fig. 2 (a) Concrete square with four predetermined breaking points restrained by a strengthened square steel profile (dimensions in mm). (b) Sample with detail of a crack

first crack occurred. As a consequence, no further cracks developed.

To study the influence of curing time and drying velocity on age of cracking, two mixtures were selected (CVC 2 and SCC 4). CVC-mixture CVC 2 and SCCmixture SCC 4 were chosen due to their difference in creep and E-modulus at comparable compressive strength. To study the influence of curing, concrete squares of the two selected mixtures were stored for varying durations at $20^{\circ} \mathrm{C}$ and $\sim 99 \%$ r.h. (wrapped in wet towels $=$ curing time) before moving them to $20^{\circ} \mathrm{C}$ 


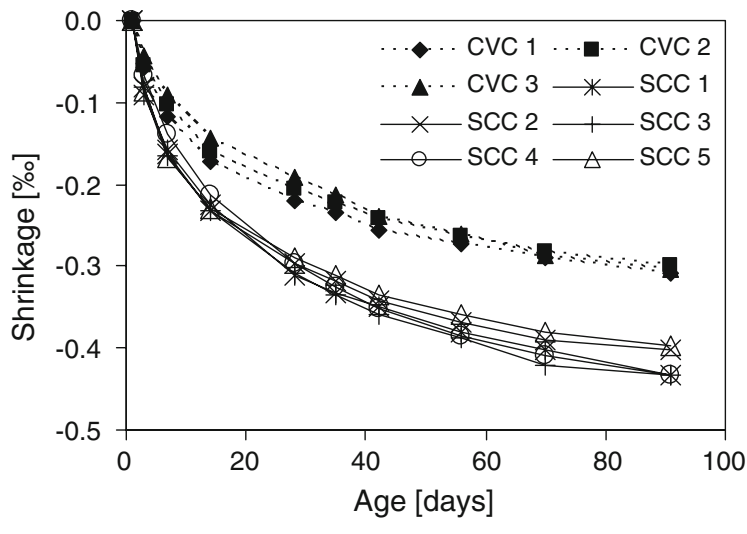

Fig. 3 Shrinkage of SCC $1 / 5$ compared to CVC $1 / 3$ up to 91 days at constant relative humidity of $70 \%$ (condition $\mathrm{K} 0$ )

and $70 \%$ r.h. (Table 3, conditions K2-K4). Furthermore, slow drying condition was simulated by storing squares of the selected mixtures at $20^{\circ} \mathrm{C}$ and $\sim 99 \%$ r.h. for 7 days, followed by 14 days curing at $20^{\circ} \mathrm{C}$ and $90 \%$ r.h. and finally storing them at $20^{\circ} \mathrm{C}$ and $70 \%$ r.h. until the crack occured (condition K5). Age of cracking in case of conditions K2-K5 was determined as the average of two squares per mixture and curing condition. At the same time, free shrinkage (start of measurements at the age of $24 \mathrm{~h}$ ) of the selected mixtures was determined on prisms $120 \mathrm{~mm} \times$
$120 \mathrm{~mm} \times 360 \mathrm{~mm}$ stored at identical conditions $\mathrm{K} 2-\mathrm{K} 5$ as the squares.

\section{Results}

\subsection{Shrinkage and creep of CVC $1 / 3$ and SCC $1 / 5$}

Shrinkage under curing condition K0 of SCC $1 / 5$ is generally higher than that of CVC $1 / 3$ at any time (Fig. 3). After 91 days shrinkage of SCC $1 / 5$ is about $30-40 \%$ higher compared to CVC $1 / 3$. This ratio is not considerably influenced either by changing $w / b$ (at constant volume of paste) of CVC or by changing water content or volume of paste of SCC.

In contrast to shrinkage there is no significant difference in creep under constant load between SCC $1 / 5$ and CVC $1 / 3$ (Table 4). Although there are differences of $60-100 \mathrm{l} / \mathrm{m}^{3}$ in volume of paste between SCC $1 / 5$ and CVC $1 / 3$, creep of SCC $1 / 5$ is only slightly higher and mainly within the variance of CVC 1/3. Creep of SCC and CVC increases with increasing $\mathrm{w} / \mathrm{b}$ and decreasing compressive strength.

Creep under increasing load is similar for CVC 2 and SCC 4 until an age of 14 days. Afterwards, SCC
Table 4 Properties of the various mixtures

Shrinkage and creep (constant load) determined under curing condition $\mathrm{K} 0$, age of cracking under condition $\mathrm{K} 1$

\begin{tabular}{lllllll}
\hline Mixture & $\begin{array}{l}\text { Compressive } \\
\text { strength } \\
\text { 28 days } \\
(\mathrm{MPa})\end{array}$ & $\begin{array}{l}\text { Flexural } \\
\text { strength } \\
28 \text { days } \\
(\mathrm{MPa})\end{array}$ & $\begin{array}{l}\text { E-modulus } \\
28 \text { days } \\
(\mathrm{MPa})\end{array}$ & $\begin{array}{l}\text { Shrinkage } \\
91 \text { days } \\
(\%)\end{array}$ & $\begin{array}{l}\text { Creep } \\
91 \text { days } \\
(\%)\end{array}$ & $\begin{array}{l}\text { Age of } \\
\text { cracking }\end{array}$ \\
\hline CVC 1 & 69.7 & 6.7 & 44,800 & -0.31 & -0.20 & 19 \\
CVC 2 & 51.2 & 5.4 & 39,000 & -0.30 & -0.25 & 31 \\
CVC 3 & 42.3 & 5.5 & 35,700 & -0.31 & -0.30 & 17 \\
SCC 1 & 61.3 & 6.3 & 35,650 & -0.43 & -0.33 & 11 \\
SCC 2 & 71.1 & 7.7 & 38,050 & -0.40 & -0.27 & 12 \\
SCC 3 & 59.0 & 6.9 & 35,350 & -0.43 & -0.32 & 11 \\
SCC 4 & 57.4 & 6.3 & 35,450 & -0.43 & -0.35 & 10 \\
SCC 5 & 74.0 & 7.2 & 40,600 & -0.40 & -0.23 & 10 \\
SCC A & 56.7 & 6.0 & 35,500 & -0.42 & -0.31 & 14 \\
SCC B & 52.1 & 5.7 & 34,850 & -0.41 & -0.27 & 17 \\
SCC C & 63.1 & 6.5 & 37,050 & -0.34 & - & 14 \\
SCC D & 50.7 & 5.7 & 34,250 & -0.38 & -0.35 & 15 \\
SCC E & 65.8 & 6.0 & 36,800 & -0.42 & - & 11 \\
SCC F & 61.2 & 6.0 & 36,650 & -0.41 & - & 11 \\
SCC G & 63.3 & 6.0 & 36,300 & -0.31 & - & 18 \\
SCC H & 58.9 & 5.9 & 36,400 & -0.26 & - & 28 \\
\hline
\end{tabular}




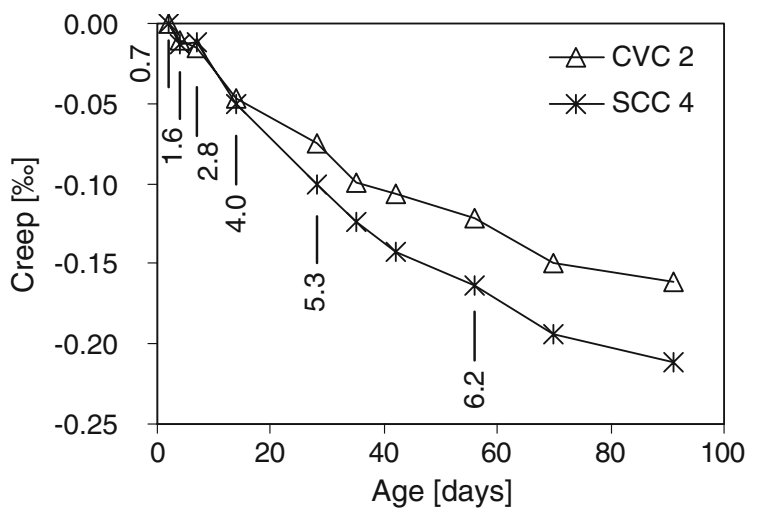

Fig. 4 Creep under increasing load according to Fig. 1 (load $=$ numbers oriented vertically in $\mathrm{MPa}$ ) for CVC 2 and SCC 4

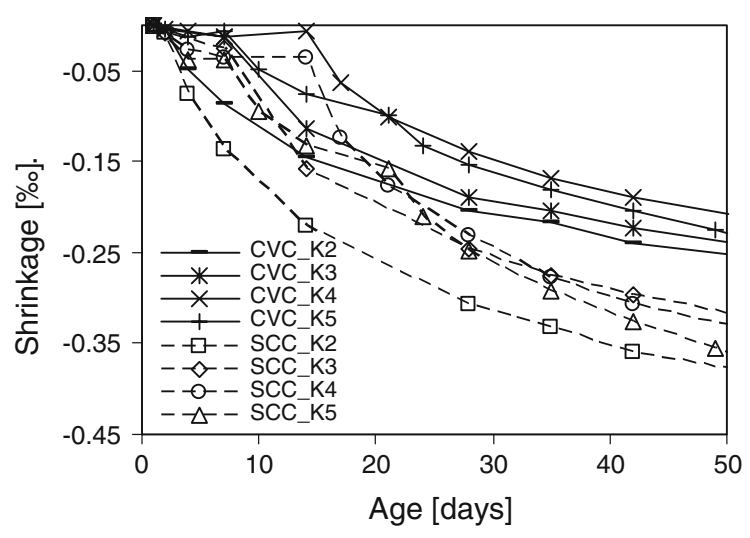

Fig. 5 Free shrinkage of prisms (SCC 4 and CVC 2) at curing conditions K2-K5

4 shows an approximately $30 \%$ higher creep rate than CVC 2 (Fig. 4).

Shrinkage under curing conditions K2-K5 is affected mostly in the early age. For 7 and 14 days curing SCC 4 shrinks about $0.04 \%$ during curing period in spite of the prevention of moisture loss (Fig. 5). Shrinkage of CVC 2 is lower under identical conditions. The end of curing is marked by a rapid increase of shrinkage for both types of concrete. At identical curing time, shrinkage of SCC is higher at any time compared to CVC.

\subsection{Shrinkage of SCC A/H compared to SCC 1}

As it can be seen in Fig. 6, the use of CEM II/A-LL and the partial substitution of CEM I by fly ash has hardly any influence on shrinkage (SCC A and B). The relative

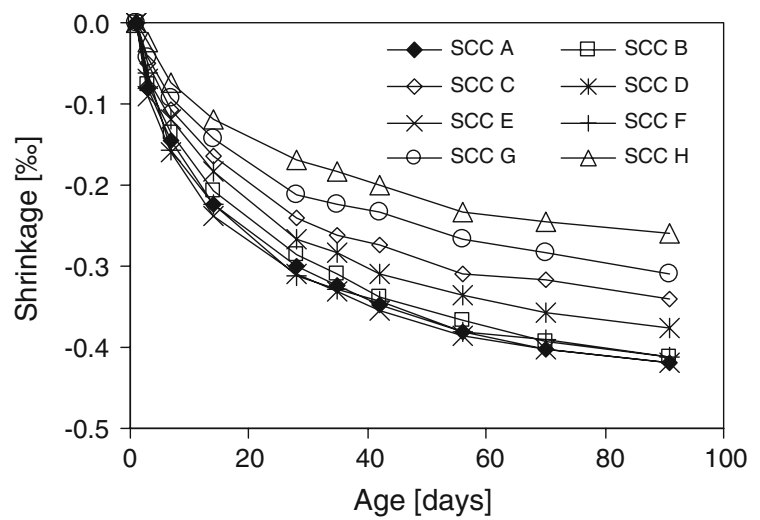

Fig. 6 Shrinkage of $\mathrm{SCC} \mathrm{A/H}$ up to 91 days at constant relative humidity of $70 \%$ (condition $\mathrm{K} 0$ )

decrease of shrinkage at 91 days of 3-5\% compared to reference mixture SCC 1 is within the range of variance of SCC 1/5. The same applies for the change of fine aggregate content (SCC E and F), where the relative decrease is $3-5 \%$ as well. The influence of a partial substitution of CEM I by limestone powder (SCC D) is slightly higher than the one of fly ash and CEM II/A-LL and allows a reduction of shrinkage of $13 \%$ compared to SCC 1 . Since fly ash improves the workability of fresh concrete [13] it is possible to decrease the w/b keeping superplastisizer content on the level of SCC 1. Due to this measure shrinkage at 91 days can be decreased about $20 \%$ (SCC C). The use of $1 \%$ or $2 \%$ SRA (SCC G and $\mathrm{H}$ ) decreases shrinkage essentially (28\% and $40 \%$ respectively) to values in the range of CVC $1 / 3$.

\subsection{Age of cracking}

The time from production to the appearance of a visible crack (age of cracking) under constant curing $\mathrm{K} 1$ is shown in Table 4. It can be seen that age of cracking of CVC is generally delayed compared to the one of SCC 1/5. Age of cracking for SCC $1 / 5$ is nearly the same (between 10 and 12 days), while age of cracking of CVC shows a big variance (17-31 days). The use of CEM II/A-LL as binder and the partial substitution of OPC by FA or LP causes a slight delay of age of cracking (SCC A, B, $\mathrm{C}, \mathrm{D}$ ), while a change of the sand/gravel-ratio has no influence on age of cracking (SCC E and F). With SRA it is possible to delay age of cracking to values in the range of CVC (SCC G and $\mathrm{H}$ ) depending on the dosage of SRA. 


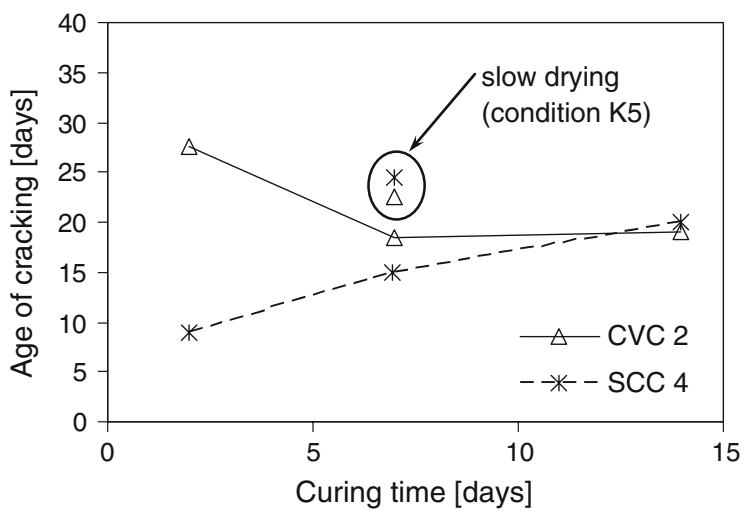

Fig. 7 Age of cracking (conditions K2-K5) versus curing time for mixtures CVC 2 and SCC 4

The squares with varying curing conditions K2K5 show differences in the age of cracking (Fig. 7). With increasing time of curing, the differences between SCC 4 and CVC 2 are getting smaller until at 14 days curing SCC cracks later than CVC.

When the squares are stored at $70 \%$ r.h. after 7 days curing (condition K3), SCC cracks about 4 days earlier than CVC. In case of storing the squares at $90 \%$ r.h. for 14 days after the same curing (condition K5), the situation changes and SCC cracks two days later than CVC.

Results of compressive strength, flexural strength and E-modulus at age of 28 days are shown in Table 4 together with the numerical values of free shrinkage and creep measurements (constant load) at 91 days under curing condition $\mathrm{K} 0$ as well as age of cracking under constant curing $\mathrm{K} 1$.

\section{Discussion}

As shown in chapter 3, there is a systematic difference between SCC and CVC concerning shrinkage. The reasons for this difference in shrinkage and its influence on cracking risk in case of restrained shrinkage deformations are discussed in the following section.

\subsection{Influence of volume of paste}

As it can be seen in Fig. 8 shrinkage is strongly related to the volume of paste. Data from [8] added in Fig. 8 emphasize this relation that has also been

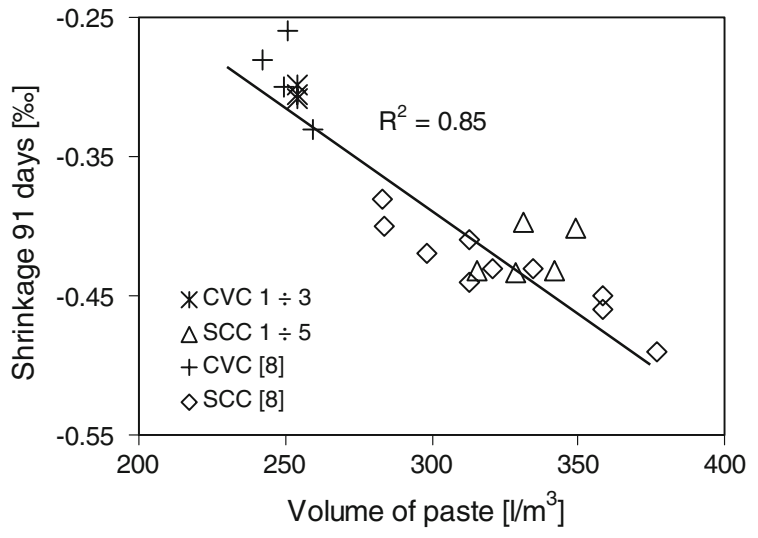

Fig. 8 Shrinkage at 91 days versus volume of paste with results of [8] added

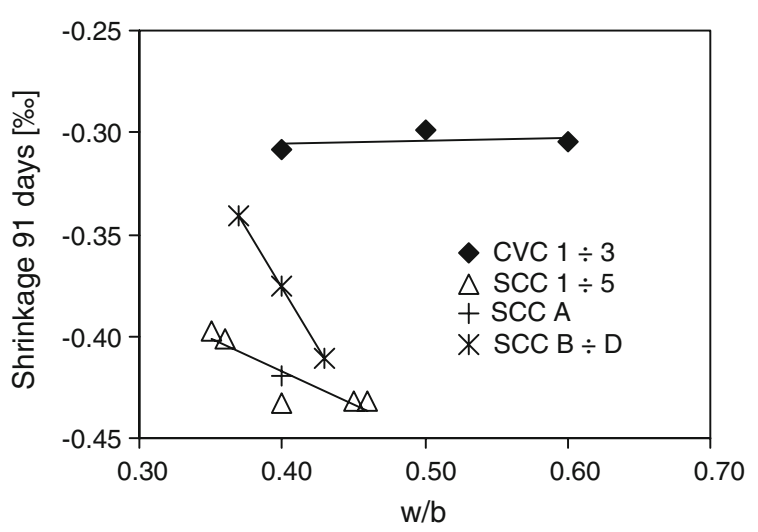

Fig. 9 Shrinkage at 91 days versus w/b for CVC 1/3, SCC $1 / 5$ and SCC with mineral admixtures (SCC B/D)

demonstrated by various other authors [7, 8, 14, 15]. There is a linear relation with a correlation coefficient of $\mathrm{R}^{2}=0.85$. An increase of the volume of paste increases shrinkage as well, explaining the systematic difference between SCC and CVC.

\subsection{Influence of w/b}

While w/b does not affect shrinkage of CVC at constant volume of paste, there is a certain influence of w/b in case of SCC (Fig. 9). The influence of w/b on shrinkage of SCC increases with increasing volume of paste (shown also in $[9,16]$ ). This is the reason why the relation between volume of paste and shrinkage of SCC 2 and SCC 3 in Fig. 8 is hardly visible. The change in volume of paste (ca. $\pm 20 \mathrm{l} / \mathrm{m}^{3}$ ) is partially compensated by the simultaneous change 
of $w / b$. These two effects interfere. Due to low w/b of SCC there can be expected a certain amount of autogenous shrinkage. However, the results clearly show that drying shrinkage is the dominating process.

The behaviour of SCC with CEM II/A-LL (SCC A) is comparable with SCC $1 / 5$. For SCC B/ $\mathrm{D}$ with higher amounts of mineral admixtures (fly ash and limestone powder respectively) the dependence of shrinkage on $\mathrm{w} / \mathrm{b}$ is even more significant. However, it would not be possible to decrease shrinkage of SCC to values of CVC used in this project by decreasing volume of paste and w/b without loosing the self-compacting abilities of the mixtures.

\subsection{Influence of various material parameters and additions}

The influence of limestone powder on shrinkage is mainly depending on its fineness [17, 18]. With a fineness higher than the one of cement it is possible to reach a higher density of the microstructure and a reduction of shrinkage. The use of CEM II/A-LL does not affect shrinkage considerably because cement and limestone are grinded together and their fineness can not be suited to each other. SCC D was produced with LP that has a higher fineness than OPC and moreover, a higher volume of cement is substituted by LP compared to mixture SCC A. This has an additional positive influence on shrinkage [15]. Therefore, shrinkage of SCC D is smaller than shrinkage of SCC A. However, the decrease of shrinkage due to LP is relatively small and it is not possible to reach values in the range of CVC. FA used in this project is coarser than cement and no densification of the microstructure occurs. Therefore, a partial substitution of cement by fly ash does hardly affect shrinkage (also shown in [15]). But the improved workability of fresh concrete due to FA allows to reduce $\mathrm{w} / \mathrm{b}$ and consequently shrinkage (Fig. 9). A change in the fine or coarse aggregate content has no substantial influence on shrinkage. Furthermore, as it is shown in [19] the difference in maximal aggregate grain size $\mathrm{d}_{\max }$ between SCC $\left(\mathrm{d}_{\max }=16 \mathrm{~mm}\right)$ und CVC $\left(\mathrm{d}_{\max }=32 \mathrm{~mm}\right)$ does not affect shrinkage when volume of paste is kept constant. By far the most effective way to reduce shrinkage of the investigated SCC is the use of a shrinkage reducing admixture (also shown in [20]). It reduces the surface tension of water in capillary pores [21-23] and consequently capillary tensions due to decreasing moisture content. Additionally, SRA has the advantage that it can be added to a proven mix design without further adaptation because its effect on workability is minor.

\subsection{Restrained shrinkage}

In principal, shrinkage stress $\sigma_{\mathrm{s}}$ depends on the degree of restraint of deformations $\mathrm{k}$, reduced $\mathrm{E}$ modulus $\mathrm{E}_{\mathrm{red}}$ and shrinkage $\varepsilon_{\mathrm{s}}$ (Eq. 1). Since shrinkage is a slow deformation process, creep can reduce the developing stress (relaxation), which is taken into account by $\mathrm{E}_{\text {red }}$ (effective E-modulus reduced due to relaxation) in the simplified Eq. 1. As soon as $\sigma_{\mathrm{s}}$ exceeds tensile strength of the concrete, cracks occur.

$\sigma_{\mathrm{s}}=\mathrm{k} \cdot \mathrm{E}_{\mathrm{red}} \cdot \varepsilon_{\mathrm{s}}$

The material properties used in Eq. 1 have been measured for concretes used in this project, while $\mathrm{k}$ (degree of restraint) is a not exactly known constant and can be omitted in the following reflections on the basis of relative comparison. As shown in [24], creep under compression and relaxation under tensile stress are in the same range. Therefore, creep measurements can be used to assess tensile stress relaxation of SCC and CVC. However, since the first loading was generally at the age of 28 days, the results enable a comparison in a qualitative manner only. Since strength class is one of the most important properties defining a concrete in practice, the mechanical properties are referred to compressive strength in the following passage.

At a given compressive strength, shrinkage of SCC $1 / 5$ is about $30-40 \%$ higher than shrinkage of CVC 1/3 (Fig. 10).

E-modulus and creep show systematic differences referred to compressive strength as well. At constant compressive strength E-modulus of CVC 1/3 is about $12-15 \%$ higher than E-modulus of SCC 1/5 (Fig. 11). The measured results show a good correlation to the results calculated with equations given in [7].

Creep (constant load applied after 28 days) of SCC $1 / 5$ is about $30-40 \%$ higher compared to CVC 1/3 at constant compressive strength (Fig. 12). According to Laube [25], the relative relaxation under tension is strongly depending on the age of concrete at first loading, but is independent of the 


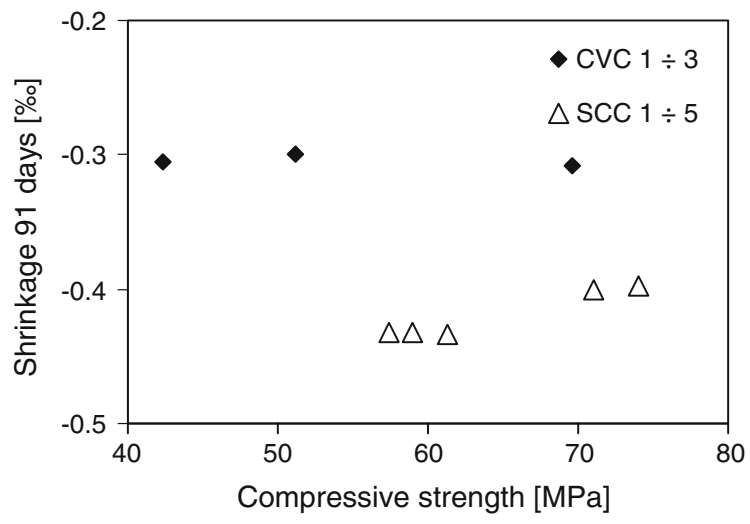

Fig. 10 Shrinkage at 91 days versus compressive strength

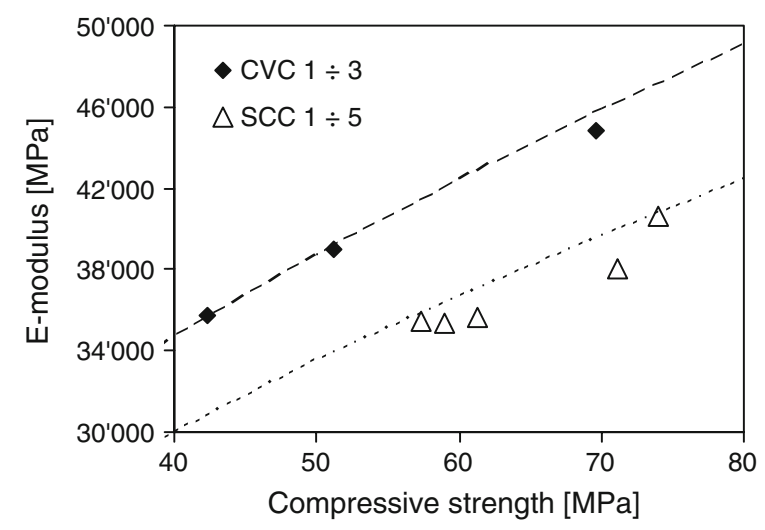

Fig. 11 E-modulus versus compressive strength. - E-modulus calculated according to [7] for CVC $\left(E=5,480 \sqrt{ } f_{c}\right)$. $\cdots \cdots$. E-modulus calculated according to [7] for SCC $\left(\mathrm{E}=4,740 \sqrt{ } \mathrm{f}_{\mathrm{c}}\right)$

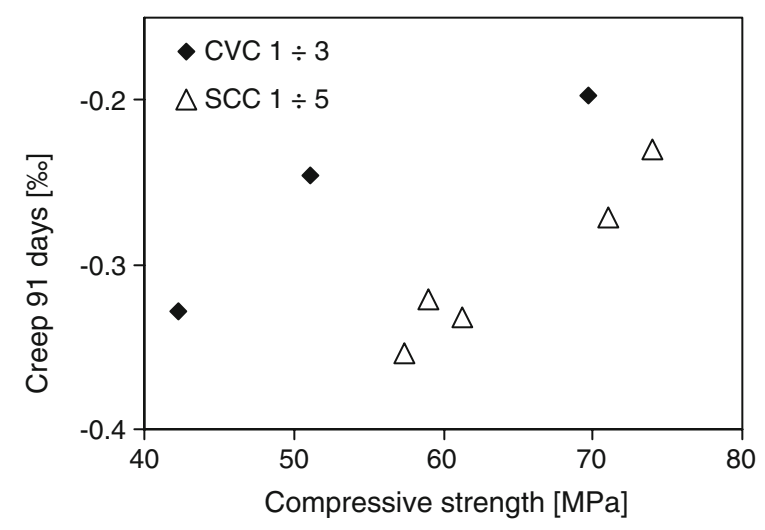

Fig. 12 Creep at 91 days versus compressive strength

applied load. However, the experiment with first loading after 2 days and variable load (Fig. 4) shows that the above mentioned differences in creep

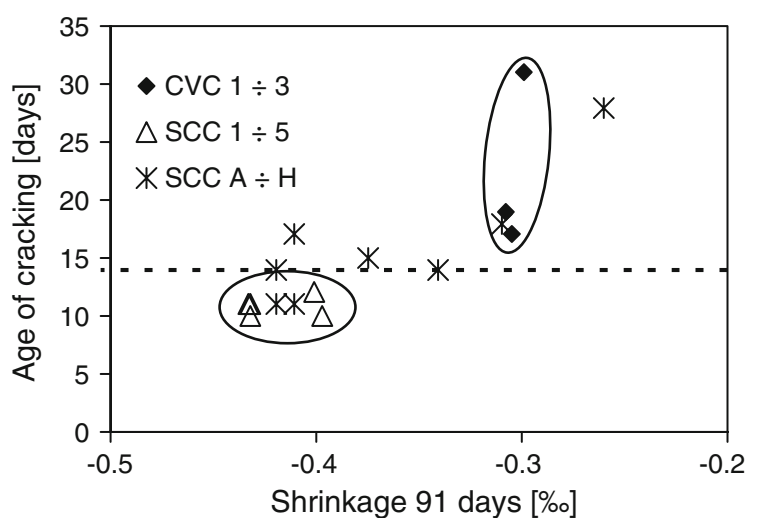

Fig. 13 Age of cracking of CVC and SCC (condition K1) versus shrinkage at 91 days. Doted line: Exposure changes from 70 to $35 \%$ r.h after 14 days. Circles: position of CVC $1 / 3$ and SCC $1 / 5$

between SCC and CVC are valid at concrete age younger than 28 days as well.

Theoretically, higher creep and lower E-modulus of SCC compared to CVC at comparable compressive strength should reduce shrinkage stress as shown in Eq. 1 and, therefore, reduce the stress difference due to higher shrinkage. But as the results indicate, the main factor influencing age of cracking in the chosen set up at constant curing $\mathrm{K} 1$ is shrinkage and neither E-modulus nor creep or tensile strength (Fig. 13). This can be attributed to the chosen set up with a high degree of restraint. Additionally, the concrete dries relatively fast due to the small specimen section and the low relative humidity. Therefore, tensile shrinkage stresses develop very fast and relaxation has hardly any influence. Moreover, for the short curing of 2 days, shrinkage stresses develop already at young concrete age where the differences in creep between SCC and CVC are only very small (Fig. 4). As a result age of cracking under these conditions mainly depends on free shrinkage.

This is supported by the good correlation between shrinkage at 91 days and age of cracking of CVC $1 / 3$ and SCC $1 / 5$ (Fig. 13). This relation is less evident in $\mathrm{SCC} \mathrm{A} / \mathrm{H}$. In general, the relation of shrinkage and age of cracking is not linear. At relatively low values a decrease in shrinkage extends age of cracking more than at relatively high values. When shrinkage falls below a certain threshold, stresses obviously never exceed tensile strength of concrete and no cracks occur. 


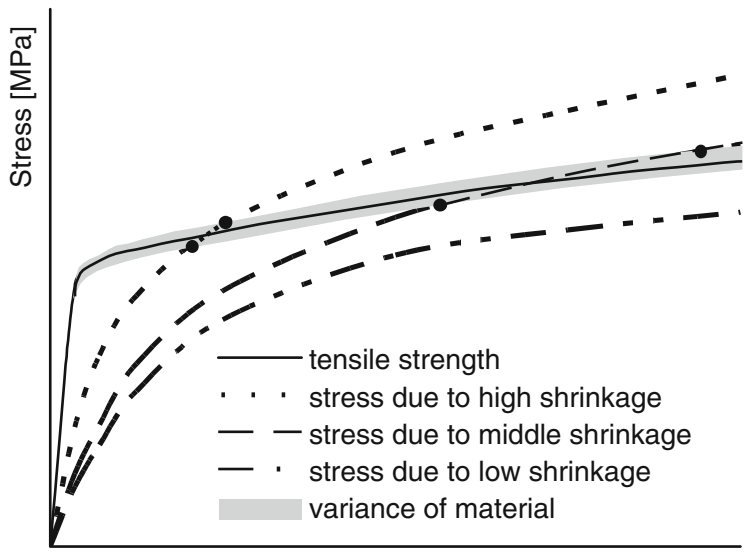

Age of concrete [days]

Fig. 14 Schematic development of tensile strength and shrinkage stress for different shrinkage values. Dots: possible age of cracking, depending on variance of material properties

This observation can be explained on the basis of the development of tensile strength and shrinkage stress with time (Fig. 14). As soon as the two curves intersect, cracks occur. With decreasing shrinkage the two curves flatten out and age of cracking increases until the two curves do intersect no longer and concrete does not crack. The later the age of cracking the higher is the influence of slight changes in shrinkage. That is the reason for the rapid increase of age of cracking with decreasing shrinkage. Furthermore, variances in material properties due to inhomogeneities in the area of the predetermined breaking points of specific samples can have a higher influence at a later age of cracking (dots in Fig. 14). The bigger maximum grain size of CVC affects the variance of age of cracking additionally. In this regard it would have been beneficial to produce more than one square per mixture for the investigations at constant curing $\mathrm{K} 1$.

When curing time is increased from 2 to 14 days, the differences in age of cracking between SCC 4 and CVC 2 decrease, although shrinkage of SCC 4 is still higher compared to CVC 2. With increasing curing time, E-modulus of CVC 2 at the end of curing is increasing while creep is decreasing at the same time. Since course of shrinkage after the end of curing is not depending on curing time considerably, shrinkage stresses are developing faster due to increased stiffness of concrete. As a consequence, CVC 2 cracks earlier at longer curing times. This behaviour has also been shown by e.g. Altoubat et al [26]. The same relations apply to SCC 4. However, SCC 4 shrinks also during curing (Fig. 5) due to autogenous shrinkage that mainly affects concrete with low w/b [9]. As a result, the prevention of drying shrinkage by curing enables a relaxation of autogenous shrinkage stress by creep. For longer curing times, drying and autogenous shrinkage are separated resulting in a decreased stress development. Together with increasing E-modulus and decreasing creep as described for CVC 2, age of cracking from the end of curing remains roughly the same for SCC 4 . These processes and the increasing differences in creep between SCC 4 and CVC 2 after 14 days (Fig. 4) seem to be the reason for decreasing differences in age of cracking with increasing curing time between SCC 4 and CVC 2.

In slow drying conditions (K5), shrinkage deformations develop slower and consequently shrinkage stress as well. Therefore, creep has a higher effect on stress relaxation than in fast drying conditions and the differences between SCC 4 and CVC 2 in creep are of higher influence. As a consequence, SCC 4 cracks later than CVC 2 under these conditions despite higher free shrinkage of SCC 4 at age of cracking.

The results indicate, that conditions resulting in a slower shrinkage stress development should lead to decreased cracking risk of SCC 4 compared to CVC 2. Shrinkage stress develops slower with decreasing degree of restraint, increasing specimen dimension and lower drying velocity. These considerations are supported by the results of other studies [27, 28].

\section{Conclusions}

The results of the study allow to draw the following conclusions:

- Shrinkage is mainly depending on volume of paste. Since the investigated SCC has a higher volume of paste (about $80 \mathrm{l} / \mathrm{m}^{3}$ ) compared to $\mathrm{CVC}$, its shrinkage is higher. At the age of 91 days the difference between SCC without SRA and CVC is $10-40 \%$.

- Changing w/b, a partial substitution of cement by FA or LP as well as a change of the fine or coarse aggregate content does not affect shrinkage of the investigated SCC-mixtures and thus cracking risk 
considerably neither in a positive nor in a negative manner.

- Using SRA it is possible to decrease shrinkage and age of cracking of SCC to values of CVC. The achieved shrinkage reduction is depending on the amount of added SRA. As a result, cracking risk is decreased as well.

- For high drying velocity and degree of restraint (e.g. thin concrete layers) shrinkage is the most important factor in regard to cracking risk of the investigated concretes in case of restrained deformations. Due to higher shrinkage, cracking risk of SCC is increased since higher creep and lower E-modulus of SCC compared to CVC at comparable compressive strength have no apparent influence on age of cracking under these conditions.

- For slow drying velocity or low degree of restraint (e.g. massive components, humid climate) shrinkage stress is considerably reduced by relaxation due to creep. Since creep of the investigated SCC is higher than CVC with comparable compressive strength, cracking risk of SCC can be lower despite higher shrinkage.

Consequently, a decrease of shrinkage rate is only one measure to reduce the risk for cracking in a concrete construction. Certainly, appropriate curing and slow drying have a positive influence as have constructional measures like low degree of restraint, appropriate reinforcing, etc. These measures should always be combined if possible.

Acknowledgements The authors would like to thank cemsuisse (Berne, Switzerland) for the financial support of the project and the staff of the lab for the different measurements.

\section{References}

1. Skarendahl A, Petersson Ö (2000) Self-compacting concrete. State-of-the-Art report of RILEM Technical Committee 174-SCC, Report 23

2. Billberg P, Petersson Ö, Österberg T (1999) Full scale casting of bridges with self-compacting concrete. In: Skarendahl A, Petersson Ö (eds) Self-compacting concrete. 1st international RILEM symposium on self-compacting concrete, Stockholm, September 1999

3. Mizobuchi T, Yanai S, Takada K, Sakata N, Nouta Y (1999) Field application of self-compacting concrete with advantageous performances. In: Skarendahl A, Petersson Ö (eds) Self-compacting concrete. 1st international RILEM symposium on self-compacting concrete, Stockholm, September 1999

4. D’Ambrosia M, Lange D, Brinks A (2005) Restrained shrinkage and creep of self-consolidating concrete. In: Shah S (ed) SCC 2005: 4th international RILEM symposium on self-compacting concrete, Chicago, November 2005

5. Graubner C-A, Lieberum K-H, Proske T (1997) Eigenschaften von selbstverdichtendem Beton. Beton- und Stahlbetonbau 12:650-656

6. Seng V, Shima H (2005) Creep and shrinkage of selfcompacting concrete with different limestone powder contents. In: Shah S (ed) SCC 2005: 4th international RILEM symposium on self-compacting concrete, Chicago, November 2005

7. Leemann A, Hoffmann C (2005) Properties of self-compacting concrete and conventional concrete-differences and similarities. Mag Concrete Res 57(6):315-319

8. Hoffmann C, Leemann A (2004) Selbstverdichtender Beton (Teil 1): Herstellung, Anwendung und Dauerhaftigkeit von selbstverdichtendem Beton. Research assignment AGB2000/481 (84/00), ASTRA

9. Neville AM (1995) Elasticity, shrinkage and creep. In: Properties of concrete, 4th edn. Longman, Essex

10. Leemann A, Hoffmann C, Olbrecht H (2001) Selbstverdichtender Beton. In: Schweizer Ingenieur- und Architektenverein (ed) tec 21(40), pp 7-12

11. EN 12350-5 (1999) Testing fresh concrete-Part 5: flow table test

12. Schweizer Ingenieur- und Architektenverein (2003) Betonbau-Ergänzende Festlegungen. Swiss Code 505(262/1)

13. Yahia A, Tanimura M, Shimabukuro A, Shimoyama Y (1999) Effect of rheological parameters on self-compactability of concrete containing various mineral admixtures. In: Skarendahl A, Petersson Ö (eds) Self-compacting concrete. 1st international RILEM symposium on selfcompacting concrete, Stockholm, September 1999

14. D'Ambrosia M, Lange D, Brinks A (2005) Restrained shrinkage and creep of self-consolidating concrete. In: Shah S (ed) SCC 2005: 4th international RILEM symposium on self-compacting concrete, Chicago, November 2005

15. Rozière E, Turcry P, Loukili A, Cussigh F (2005) Influence of paste volume, addition content and addition type on shrinkage cracking of self-compacting concrete. In: Shah S (ed) SCC 2005: 4th international RILEM symposium on self-compacting concrete, Chicago, November 2005

16. Persson B (2003) Shrinkage of concrete. In: Bentur A (ed) Early age cracking in cementicious systems. Report of RILEM Technical Committee TC 181-EAS, pp 89-99

17. Bui VK, Montgomery D (1999) Drying shrinkage of selfcompacting concrete containing milled limestone. In: Skarendahl A, Petersson Ö (eds) Self-compacting concrete. 1st international RILEM symposium on self-compacting concrete, Stockholm, September 1999

18. Klug Y, Holschemacher K (2003) Comparison of the hardened properties of self-compacting and normal vibrated concrete. In: Wallevik O, Nielsson I (eds) Selfcompacting concrete. 3rd International RILEM symposium on self-compacting concrete, Reykjavik, August 2003 
19. Leemann A, Romer M (2001) Selbstverdichtender Beton mit Fasern. EMPA-report No. 201,687, EMPA, Dübendorf

20. Wombacher FJ (1999) Shrinkage and shrinkage reduction of self compacting concrete. In: Skarendahl A, Petersson Ö (eds) Self-compacting concrete. 1st international RILEM symposium on self-compacting concrete, Stockholm, September 1999

21. Rongbing B, Jian S (2005) Synthesis and evaluation of shrinkage-reducing admixture for cementitious materials. Cement Concrete Res 35:445-448

22. Bentz DP, Geiker MR, Hansen KK (2001) Shrinkagereducing admixtures and early-age desiccation in cement pastes and mortars. Cement Concrete Res 31:1075-1085

23. Weiss J, Berke N (2003) Admixtures for reduction of shrinkage and cracking. In: Bentur A (ed) Early age cracking in cementicious systems. Report of RILEM Technical Committee TC 181-EAS, pp 323-335
24. Gutsch AW (2002) Properties of early age concreteexperiments and modelling. Mater Struct 35:76-79

25. Laube M (1990) Werkstoffmodell zur Berechnung von Temperaturspannungen in massigen Betonbauteilen im jungen Alter. Dissertation, University of Braunschweig

26. Altoubat SA, Lange DA (2001) Creep, shrinkage and cracking of restrained concrete at early age. ACI Mater J 98:323-331

27. Weiss WJ, Shah SP (2002) Restrained shrinkage cracking: the role of shrinkage reducing admixtures and specimen geometry. Mater Struct 35:85-91

28. Hossain AB, Weiss J (2006) The role of specimen geometry and boundary conditions on stress development and cracking behaviour in the restrained ring test. Cement Concrete Res 36:189-199 